\title{
Assessing wind induced stay vibrations in bridges
}

\author{
Pietro Croce, Paolo Formichi, Filippo Landi, Roberto Castelluccio
}

\begin{abstract}
Stay vibration events have been reported all over the world on cable-stayed bridges. Cable vibrations cause bridge users discomfort and may also lead to bridge collapse. Aim of this study is to investigate relevant cable vibration phenomena directly induced by wind, such as buffeting, von Kármán vortex-shedding, dry inclined galloping and rain wind induced vibrations. The results are presented in terms of required necessary damping to control the dynamic stability of stays for a significant case study.
\end{abstract}

Keywords - cable-stayed bridge, cable vibrations, aerodynamics, bluff bodies

\section{Introduction}

Cable-stayed bridges became very popular during the second half of the twentieth century. There are four main reasons that lead to an enormous increase in the construction of cable-stayed bridges [1]: cable-stayed bridges are stiffer than suspension bridges, they are adequate for construction in weak soil due to their self-balancing features, they are economically advantageous for moderate to large spans and they have remarkable aesthetic qualities. Moreover, recent improvements in cable technology and in erection techniques allows to design increasingly large and slender cable-stayed bridges; considering in addition that stay cables are very flexible elements, with small damping coefficients $(\xi \leq 0.50 \%)$ it is clear that these elements are very vulnerable to vibrations under dynamic loads.

Cable vibrations alarm bridge users (especially pedestrian users) with a subsequent discomfort, but these can also cause a fatigue damage. The first significant report on cable vibration dates back to 1976 [2]: in effect, during the erection of the Brotonne bridge (France) longer cables hit each other, due to vibrations, and the problem was solved mounting viscous dampers close to the deck anchorages [1]. In the subsequent years many vibration problems occurred in bridges all over the world and then started an intensive research on this issue.

Relevant cable vibration phenomena induced by wind are discussed here, referring to a significant case study.

\section{Cable vibration phenomena directly induced by wind}

Among cable vibration phenomena directly induced by wind, there are Buffeting, von Kármán Vortex-Shedding and Dry Inclined Galloping: the first refers to forced vibrations caused by unsteady wind gusts, the second is characterized by an alternate shedding of vortices at the top and bottom surfaces of cables and the third is an aeroelastic

Pietro Croce, Paolo Formichi, Filippo Landi, Roberto Castelluccio University of Pisa, Department of Civil and Industrial Engineering Structural Division Italy phenomenon typical of yawed circular stay, where the appearance of an axial flow behind cables for certain yawing angles alters the section radial symmetry. Then there are Rain-Wind Induced Vibrations: under combination of rain and wind, oscillating rivulets form at the upper and lower surfaces of the cable altering section radial symmetry (Fig. 1).

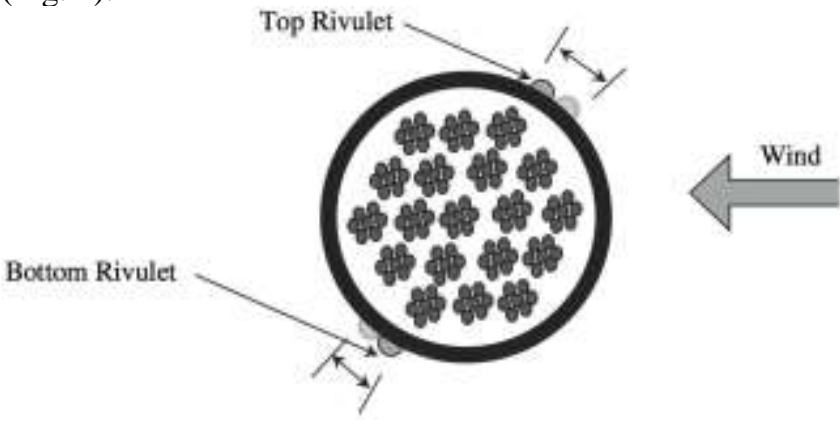

Figure 1. Cross section of a cable with upper and lower rivulet, from [3]

In these cases an aerodynamic instability is possible, due to symmetry loss. Indeed, when the angle of attack $\beta$ of the wind is small $(\beta \approx 0)$, the so-called classical Den Hartog [4] necessary condition for incipient galloping instability is

$$
\left(\frac{\mathrm{d} C_{\mathrm{L}}}{\mathrm{d} \beta}+C_{\mathrm{D}}\right)_{\beta \approx 0}<0
$$

where $C_{\mathrm{L}}$ is the lift coefficient and $C_{\mathrm{D}}$ is the drag coefficient. Obviously, circular cross sections are never subjected to galloping, as the variation of $C_{\mathrm{L}}$ is always null, due to symmetry, and drag coefficient $\left(C_{\mathrm{D}}\right)$ is always positive.

When (1) is satisfied, the overall system damping $(d)$ may be negative because aerodynamic damping becomes negative:

$$
d=2 m \omega \xi+\frac{1}{2} \rho U D\left(\frac{\mathrm{d} C_{\mathrm{L}}}{\mathrm{d} \beta}+C_{\mathrm{D}}\right)_{\beta \approx 0}
$$

being $m$ the cable mass per unit length, $\omega$ the natural circular frequency, $\xi$ the damping ratio, $\rho=1.2 \mathrm{~kg} / \mathrm{m}^{3}$ the air density at $20^{\circ} \mathrm{C}, U$ is the uniform wind velocity and $D$ is the diameter of the cable.

\section{The case study}

Wind induced vibrations are assessed here referring to a cable-stayed bridge crossing the river Arno in Figline Valdarno, a town near Florence [5]. This self-anchored cable-stayed bridge has a total length of $281 \mathrm{~m}$ with three spans respectively of $44 \mathrm{~m}, 37 \mathrm{~m}$ and $200 \mathrm{~m}$ (Fig. 2). The S355 steel box girder has a trapezoidal cross section, $2.00 \mathrm{~m}$ depth and $14.96 \mathrm{~m}$ width (Fig. 3). The $12 \mathrm{~mm}$ thick orthotropic steel deck is reinforced with trapezoidal stiffeners spaced $600 \mathrm{~mm}$ center to center. 
The deck is suspended to a pylon via 17 pairs of lockedcoil strands forming an asymmetric semi-fan; these cables are $15.00 \mathrm{~m}$ spaced on the girder and $3.75 \mathrm{~m}$ on the pylon. The concrete A-shaped pylon has a total height of $96.00 \mathrm{~m}$.
All substructures are founded on piles with a diameter of $1.60 \mathrm{~m} . \mathrm{S}$

Structural analysis was carried out with $\mathrm{SAP} 2000^{\circledR}$.

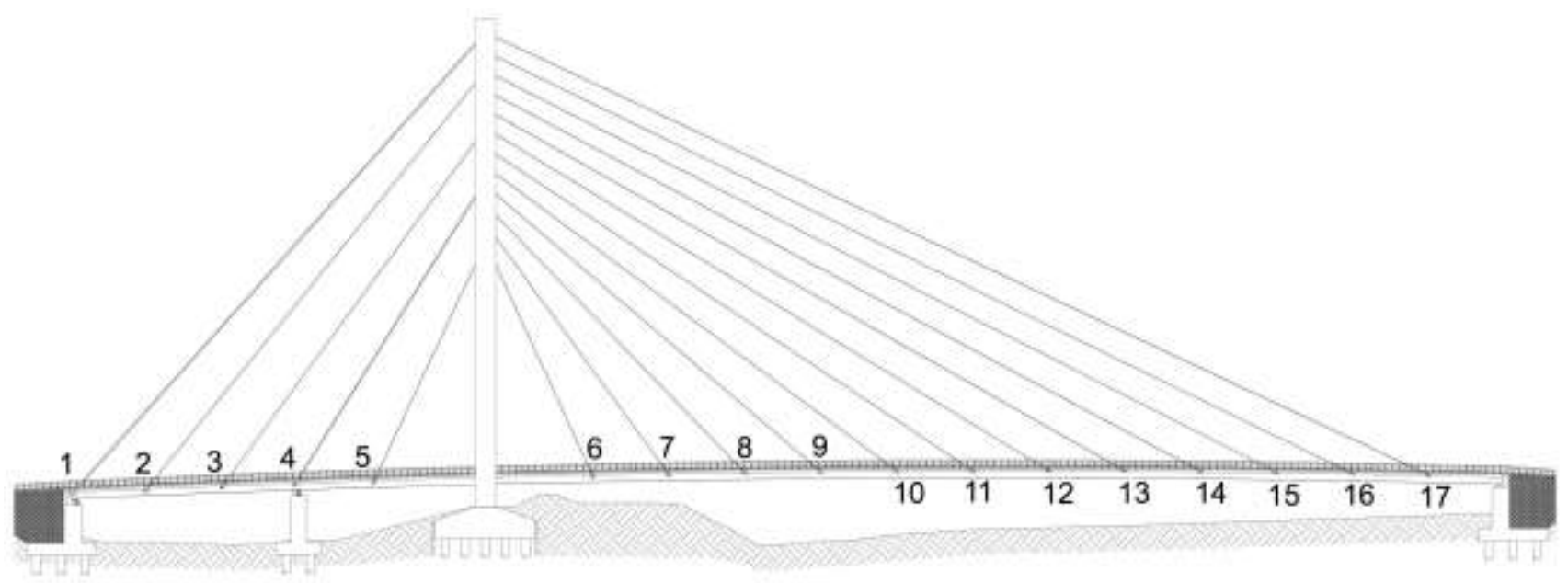

Figure 2. The cable-stayed bridge analyzed

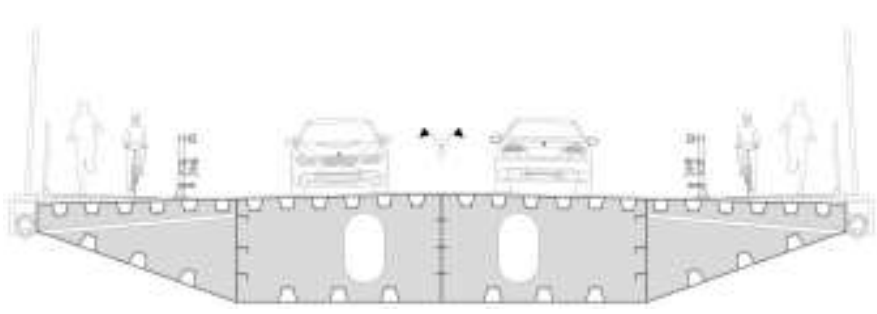

Figure 3. The bridge deck.

\section{Iv. Case study analysis}

\section{A. Natural frequencies of cables}

The $n$-th cable circular frequency can be evaluated with Mehrabi and Tabatabai formula [6],

$$
\omega_{n}=\frac{\pi n}{l} \sqrt{\frac{T}{m}}\left(\alpha \beta_{n}-0.24 \frac{\mu}{\zeta}\right),
$$

where sag and bending stiffness effects are introduced in vibrating chord theory by means of the dimensionless coefficients $\alpha, \beta_{n}, \mu$ and $\zeta[6]$ :

$$
\begin{gathered}
\alpha=1+0.039 \mu \\
\beta_{n}=1+\frac{2}{\zeta}+\frac{4+\frac{n \pi^{2}}{2}}{\zeta^{2}}
\end{gathered}
$$

$$
\zeta=\sqrt{\frac{T l^{2}}{E J}}
$$

$T$ is the component of cable tension along cable chord in the dead load configuration;

$l$ is the horizontal projection of cable;

$E$ is Young's modulus of cable material;

$J \quad$ is the 2nd area moment of cable cross section;

$\mu$ is a coefficient varying with $n$ :

$$
\begin{array}{ll}
\mu=\lambda^{2} & \text { if } n=1 \\
\mu=0 & \text { if } n>1 \text { (in-plane modes) } \\
\mu=0 & \text { for out-of-plane modes. }
\end{array}
$$

$\lambda^{2}$ is a parameter, introduced by Irvine [7], including both the geometric and deformational characteristics of a suspended cable and defined as

$$
\lambda^{2}=\left(\frac{m g L}{T}\right)^{2} \frac{L}{L_{\mathrm{e}}} \frac{E A_{0}}{T}
$$

where

$L$ is the chord length;

$A_{0}$ is the area of undeformed cable cross section;

$L_{\mathrm{e}}$ is a virtual length of cable, defined by

$$
L_{\mathrm{e}}=\int_{0}^{L}\left(\frac{\mathrm{d} s}{\mathrm{~d} x}\right)^{3} \mathrm{~d} x
$$


$f \quad$ is the cable sag at midpoint.

As known, for shallow cables $(f / L \leq 1 / 8)$ the catenary can be approximated by an elastic parabola, so

$$
\begin{gathered}
L_{\mathrm{e}} \approx L\left[1+8\left(\frac{f}{L}\right)^{2}\right] \\
f=\frac{m g L^{2}}{8 T} .
\end{gathered}
$$

The accuracy of (3) is higher for cables with $\zeta \geq 50$ and $\lambda^{2}<3.1$ : if $\zeta<50$ bending stiffness can be disregarded, if $\lambda^{2} \geq 3.1$ cables are relatively flabby and vibrating chord theory is not acceptable.

Table I and Table II show the Irvine parameter and fundamental frequencies (in-plane and out-of-plane) of stays.

\begin{tabular}{|c|c|c|c|c|c|c|c|c|c|c|}
\hline Stay & $\stackrel{T}{T}$ & $\begin{array}{l}\theta \\
(0)\end{array}$ & $\begin{array}{c}m \\
(\mathrm{~kg} / \mathrm{m})\end{array}$ & $\begin{array}{c}L \\
\text { (in) }\end{array}$ & $\begin{array}{c}1 \\
(m)\end{array}$ & $\underset{\langle m\rangle}{f}$ & $\begin{array}{l}L \\
(m)\end{array}$ & $\begin{array}{c}A_{0} \\
\left\langle\mathrm{~m}^{2}\right\rangle\end{array}$ & $\begin{array}{c}E \\
\left(\mathrm{kN} / \mathrm{m}^{2}\right)\end{array}$ & $\begin{array}{l}x^{2} \\
(\rightarrow)\end{array}$ \\
\hline 1 & 7335 & 45 & 300 & 122 & 81 & 0.750 & 122 & 0.03740 & $1.8 \times 10^{*}$ & 2.211 \\
\hline 2 & 942 & 51 & 17 & 106 & 66 & 0.247 & 106 & 0.00200 & $1.8 \times 10^{4}$ & 0.138 \\
\hline 3 & 798 & 54 & 17 & 88 & 51 & 0,198 & 85 & 0.00200 & $1.8 \times 10^{6}$ & 0.154 \\
\hline 4 & 10318 & 58 & 300 & 69 & 36 & 0.172 & 6 & 0.05740 & $1.8 \times 10^{\circ}$ & 0.256 \\
\hline 5 & 964 & 60 & 20 & $\pi 2$ & 21 & 0.069 & 52 & 0.00249 & $1.8 \times 10^{\circ}$ & 0.052 \\
\hline 6 & 965 & 65 & 24 & 51 & 22 & 0.078 & $\Delta 1$ & 0.00292 & $1.8 \times 10^{3}$ & 0.081 \\
\hline 7 & 707 & 54 & 24 & 62 & 37 & 0.156 & 62 & 0.00292 & $18 \times 10^{*}$ & $0.3 n 2$ \\
\hline 8 & 821 & 96 & 24 & 74 & 52 & 0.193 & 74 & 0.00292 & $1.8 \times 10^{*}$ & 0.278 \\
\hline 9 & 971 & 41 & 27 & 68 & 67 & $0.26 \cdot 4$ & 88 & 0.00339 & $1.8 \times 10^{*}$ & 0.365 \\
\hline 10 & 1062 & 37 & 27 & 100 & 82 & 0.325 & 102 & 0.00339 & $1.8 \times 10^{6}$ & 0.375 \\
\hline II & 1123 & 34 & 27 & 116 & 97 & 0.401 & 116 & 0.00339 & $1.8 \times 10^{6}$ & D.414 \\
\hline 12 & 1334 & 31 & 31 & 131 & 112 & 0.493 & 131 & 0.00369 & $1.8 \times 10^{5}$ & D.4T6 \\
\hline 13 & 1353 & 30 & 31 & 146 & 127 & 0.589 & 146 & 0.00389 & $1.8 \times 10^{5}$ & 0.530 \\
\hline 14 & 1425 & 26 & 31 & 161 & 142 & 0.6994 & 161 & 0.003 в9 & $1.8 \times 10^{t}$ & 0.555 \\
\hline 15 & 1300 & 27 & 31 & 176 & 157 & 0.791 & 176 & 000389 & $1.8 \times 10^{4}$ & 0.605 \\
\hline 16 & 1499 & 26 & 31 & $19 \mathrm{t}$ & 172 & 0.935 & 191 & 0.00389 & $1.8 \times 10^{5}$ & 0.715 \\
\hline 17 & 1628 & 25 & 23 & 206 & 187 & 0.872 & 206 & 0.00339 & $1.8 \times 10^{5}$ & 0.42! \\
\hline
\end{tabular}

TABLE I. IRVINE PARAMETER OF STAYS

\begin{tabular}{|c|c|c|c|c|c|c|c|c|}
\hline Stiny & $\begin{array}{c}D \\
(\mathrm{~mm})\end{array}$ & $\begin{array}{c}J \\
\left(\mathrm{~m}^{4}\right)\end{array}$ & $(5)$ & $\stackrel{\mu}{\rightarrow}$ & $\stackrel{\alpha}{\leftrightarrow}$ & $\begin{array}{l}\beta_{1} \\
(-)\end{array}$ & $\begin{array}{c}\omega_{1, \text { in }} \\
(\mathrm{rad} / \mathrm{s})\end{array}$ & $\begin{array}{l}\omega_{1, \mathrm{mut}} \\
(\mathrm{rad} / \mathrm{s})\end{array}$ \\
\hline 1 & 230 & $1.17 \times 10^{-4}$ & 52.22 & 2.211 & $1.086 \mathrm{i}$ & 1.042 & 4.50 & 4.18 \\
\hline 2 & 55 & $3.82 \times 10^{-7}$ & 266.95 & 0.138 & 1.005 & 1.008 & 7.09 & 7,06 \\
\hline 3 & 55 & $3.82 \times 10^{-5}$ & 190.09 & 0.154 & $1.006 \mathrm{i}$ & 1.011 & 7.94 & 7.90 \\
\hline 4 & 230 & $1.17 \times 10^{-4}$ & 27.66 & 0.256 & 1.010 & 1.084 & 0.17 & 9.09 \\
\hline 5 & 60 & $5.41 \times 10^{-5}$ & 72.90 & 0.052 & 1.002 & 1.029 & 13.70 & 13.68 \\
\hline 6 & 65 & $7.45 \times 10^{-7}$ & 63.17 & 0.081 & 1.003 & 1.034 & 1298 & 12.90 \\
\hline 7 & 65 & $7.45 \times 10^{-7}$ & 91.44 & 0.302 & 1.012 & 1.023 & 9.12 & 9.02 \\
\hline 8 & 65 & $7.45 \times 10^{-7}$ & 138.52 & 0.278 & 1.011 & 1.015 & B. 11 & 8.03 \\
\hline 9 & 70 & $1.00 \times 10^{-6}$ & 167.94 & 0.365 & 1.014 & 1.012 & 6.95 & 6.85 \\
\hline 10 & 70 & $1.00 \times 10^{-0}$ & 215.13 & 0.375 & 1,015 & 1.009 & 6.25 & 6.16 \\
\hline 11 & 70 & $1.00 \times 10^{-6}$ & 261.83 & 0.414 & 1.016 & 1.008 & 5.63 & 5,54 \\
\hline 12 & 75 & $1.32 \times 10^{-6}$ & 287.15 & 0.476 & 1,019 & 1.007 & 5.08 & 4.99 \\
\hline 13 & 75 & $1.32 \times 10^{-1}$ & 331.64 & 0,530 & 1.021 & 1,006 & 4.65 & 4.56 \\
\hline 14 & 75 & $1.32 \times 10^{-6}$ & 376.89 & 0.585 & 1.023 & 1.005 & 4.29 & 4.20 \\
\hline 15 & 75 & $1.32 \times 10^{-1}$ & 427.17 & 0.605 & 1.024 & 1.005 & 4.02 & 3.93 \\
\hline 16 & 75 & $1.32 \times 10^{-6}$ & 467.90 & 0.715 & 1.023 & 1,004 & 2.71 & 3.61 \\
\hline 17 & 70 & $1.00 \times 10^{-6}$ & 608.67 & 0.429 & 1,017 & 1.003 & 3.80 & 3.74 \\
\hline
\end{tabular}

TABLE II. FUNDAMENTAL CIRCULAR FREQUENCIES OF STAYS

\section{B. Buffeting}

In most circumstances buffeting is restrained from aerodynamic damping that is proportional to the uniform wind velocity both in along-wind direction, (11), and in across-wind direction, (12).

$$
\xi_{\mathrm{aer}, \mathrm{kD}}=\frac{\rho U D C_{\mathrm{D}}}{2 m \omega_{k}}
$$

$$
\xi_{\mathrm{aer}, \mathrm{kL}}=\frac{\rho U D C_{\mathrm{D}}}{4 m \omega_{k}}
$$

Drag coefficient for a circular section varies with the Reynolds Number, $R e=U D / v$, where $v$ is the kinematic viscosity of the air, whose value at $20^{\circ} \mathrm{C}$ is $0.15 \mathrm{~cm}^{2} / \mathrm{s}$. In the supercritical region $\left(R e>10^{6}\right)$, it results $C_{\mathrm{D}}=0.7$. The reference wind velocity (return period of 50 years) for construction site is $27 \mathrm{~m} / \mathrm{s}$ (97 kmph). Table III shows that,

\begin{tabular}{|c|c|c|c|c|c|c|c|c|c|}
\hline \multirow[b]{2}{*}{ Stay } & \multirow[b]{2}{*}{$\underset{(\min )}{D}$} & \multirow[b]{2}{*}{$\begin{array}{c}m \\
(\mathrm{~kg} / \mathrm{m})\end{array}$} & \multirow[b]{2}{*}{$\underset{(\mathrm{milim} / \mathrm{s})}{\mathrm{m}^{2}}$} & \multicolumn{3}{|c|}{$U=15 \mathrm{~m} / \mathrm{s}$} & \multicolumn{3}{|c|}{$U=30 \mathrm{~m} / \mathrm{s}$} \\
\hline & & & & $\begin{array}{l}A 6 \\
(-)\end{array}$ & $\begin{array}{l}C_{D} \\
\Leftrightarrow\end{array}$ & $\begin{array}{c}E_{\text {art }, s 0} \\
(\%)\end{array}$ & $\begin{array}{l}R e \\
(\rightarrow)\end{array}$ & $\begin{array}{l}C_{D} \\
(-)\end{array}$ & $\begin{array}{c}\varepsilon_{\text {inen ID }} \\
(\%)\end{array}$ \\
\hline 1 & 230 & 300 & 4,50 & $2.3 \times 10^{8}$ & 0.7 & 0.11 & $46 \times 10^{4}$ & 0.7 & 0.21 \\
\hline 2 & 50 & 17 & 700 & $5.5 \times 10^{7}$ & 0.7 & 0.29 & $11 \times 10^{4}$ & 0.7 & 0.58 \\
\hline 3 & 55 & 17 & 7.94 & $5.5 \times 10^{7}$ & 0.7 & 0.26 & $1.1 \times 10^{4}$ & 0.7 & 0.52 \\
\hline 4 & 230 & 300 & 9.17 & $2.3 \times 10^{5}$ & 0.7 & 0,05 & $4.6 \times 10^{4}$ & 0.7 & 0.11 \\
\hline 5 & 60 & 20 & 13.70 & $6.0 \times 10^{7}$ & 0.7 & 0.14 & $1.2 \times 10^{4}$ & 0.7 & 0.28 \\
\hline 6 & 65 & 24 & 12.93 & $6.5 \times 10^{\top}$ & 0.7 & 0.13 & $13 \times 10^{4}$ & 0.7 & 0.27 \\
\hline 7 & 65 & 24 & 9.12 & $6.5 \times 10^{7}$ & 0.7 & 0.19 & $1.3 \times 10^{4}$ & 0.7 & 0.38 \\
\hline 8 & 65 & 24 & 8.11 & 6.5 $\times 10^{\top}$ & 0.7 & 0.21 & $1.3 \times 10^{3}$ & 0.7 & 0.43 \\
\hline 9 & 70 & 27 & 6.95 & $7.0 \times 10^{\top}$ & 0.7 & 0.23 & $1.4 \times 10^{8}$ & 0.7 & 0.47 \\
\hline 10 & 70 & 27 & 6.25 & $7.0 \times 10^{7}$ & 0.7 & 0.26 & $14 \times 10^{4}$ & 0.7 & 0.52 \\
\hline 11 & 70 & 27 & 5.63 & $7.0 \times 10^{\top}$ & 0.7 & 0.29 & $1.4 \times 10^{5}$ & 0.7 & 0.58 \\
\hline 12 & 75 & 31 & 5.08 & $7.5 \times 10^{7}$ & 07 & 0.30 & $15 \times 10^{8}$ & 0.7 & 0.59 \\
\hline 13 & 75 & 31 & 465 & $7.5 \times 10^{7}$ & 0.7 & 0.32 & $15 \times 10^{8}$ & 0.7 & 065 \\
\hline 14 & 75 & 31 & 4.29 & $7.5 \times 10^{7}$ & 0.7 & 0.35 & $15 \times 10^{8}$ & 0.7 & 0.70 \\
\hline 15 & 75 & 31 & 4.02 & $7.5 \times 10^{7}$ & 0.7 & 0.38 & $1.5 \times 10^{8}$ & 0.7 & 0.75 \\
\hline 16 & 75 & 31 & 3.71 & $7.5 \times 10^{7}$ & 0.7 & 0.41 & $15 \times 10^{4}$ & 0.7 & 0.81 \\
\hline 17 & 70 & 27 & 3.80 & $7.0 \times 10^{7}$ & 0.7 & 0.43 & $14 \times 10^{8}$ & 0.7 & 0.85 \\
\hline
\end{tabular}
for this case, along-wind aerodynamic damping is in the range $(0.05 \div 0.45) \%$ considering $U=15 \mathrm{~m} / \mathrm{s}=54 \mathrm{kmph}$.

TABLE III. ALONG-WIND AERODYNAMIC DAMPING.

These values are consistent with literature values obtained from field observations [1]. Notice that $\xi_{\mathrm{aer}, \mathrm{kD}}=2 \xi_{\mathrm{aer}, \mathrm{kL}}$ so vibrations often occur in the plane of cables.

\section{C. von Kármán Vortex-Shedding}

The shedding frequency of vortices is governed by the Strouhal law:

$$
f_{\mathrm{v}}=\frac{U S t}{D} \text {. }
$$

Strouhal number ( St ) varies with the shape of cable cross section and on circular cylinder $S t=0.2$ for $10^{5} \leq R e \leq 10^{7}$ [8]. Provided that lock-in cannot occur, i.e. $f_{\mathrm{v}}$ (13) is sufficiently far to some cable frequencies to exclude synchronization between these frequencies, producing additional across-wind loads, this linear law applies to Scruton number

$$
S c=\frac{2 \delta m_{\mathrm{e}}}{\rho D^{2}}>20
$$

where 


$$
\delta=\ln \frac{a_{n}}{a_{n+1}}=\frac{2 \pi \xi}{\sqrt{1-\xi^{2}}} \approx 2 \pi \xi
$$

is the logarithmic decrement of structural damping $(\xi)$ and $m_{\mathrm{e}}$ is an equivalent mass per unit length (for an uniform cylinder $m_{\mathrm{e}}=m$ ).

The analysis assumes $\delta=0.1$ as representative for oscillation in the first mode $[9,10]$.

Table IV shows the Scruton number of stays and the size of lock-in region with reference to first in-plane vibration mode, evaluated according to [11]

$$
\begin{gathered}
U_{\text {lock }, \text { bot }}=5.0 f_{n} D \\
U_{\text {lock,top }}=6.2 f_{n} D,
\end{gathered}
$$

demonstrating that lock-in is undoubtedly precluded and

\begin{tabular}{|c|c|c|c|c|c|c|c|}
\hline Stay & $\begin{array}{c}\text { Yawing angle } \\
\text { (०) }\end{array}$ & $\begin{array}{c}D \\
(\mathrm{~mm})\end{array}$ & $\begin{array}{c}m \\
(\mathrm{~kg} / \mathrm{m})\end{array}$ & $\begin{array}{l}f_{1, \mathrm{in}} \\
(\mathrm{Hz})\end{array}$ & $\begin{array}{c}U_{\text {lock, bot }} \\
(\mathrm{m} / \mathrm{s})\end{array}$ & $\begin{array}{c}U_{\text {bock,top }} \\
(\mathrm{m} / \mathrm{s})\end{array}$ & $\begin{array}{l}S c \\
(-)\end{array}$ \\
\hline 1 & 3.4 & 230 & 300 & 0.717 & 0.82 & 1.02 & 95 \\
\hline 2 & 3.5 & 55 & 17 & 1.129 & 0,31 & 0.38 & 93 \\
\hline 3 & 3.2 & 55 & 17 & 1.264 & 0.35 & 0.43 & 93 \\
\hline 4 & 2.7 & 230 & 300 & 1.459 & 1.68 & 2,08 & 95 \\
\hline 5 & 1.4 & 60 & 20 & 2.181 & 0.65 & 0.81 & 93 \\
\hline 6 & 1.4 & 65 & 24 & 2.059 & 0.67 & 0.83 & 93 \\
\hline 7 & 1.4 & 65 & 24 & 1.451 & 0.47 & 0.58 & 93 \\
\hline 8 & 1.5 & 65 & 24 & 1.291 & 0.42 & 0.52 & 93 \\
\hline 9 & 1.5 & 70 & 27 & 1.106 & 0.39 & 0.48 & 93 \\
\hline 10 & 1.5 & 70 & 27 & 0.995 & 0.35 & 0.43 & 93 \\
\hline 11 & 1.5 & 70 & 27 & 0.895 & 0.31 & 0.39 & 93 \\
\hline 12 & 1.5 & 75 & 31 & 0.809 & 0.30 & 0.38 & 93 \\
\hline 13 & 1.5 & 75 & 31 & 0.740 & 0.28 & 0.34 & 93 \\
\hline 14 & 1.5 & 75 & 31 & 0.683 & 0.26 & 0.32 & 93 \\
\hline 15 & 1.5 & 75 & 31 & 0.640 & 0.24 & 0.30 & 93 \\
\hline 16 & 1.5 & 75 & 31 & 0.591 & 0.22 & 0.27 & 93 \\
\hline 17 & 1.5 & 70 & 27 & 0.605 & 0.21 & 0.26 & 98 \\
\hline
\end{tabular}
wind critical velocities are too low to generate vibrations.

TABLE IV. LOCK-IN REGION AND SCRUTON NUMBER OF STAYS

\section{Dry Inclined Galloping}

Dry inclined galloping is characterized by the occurrence of large amplitude motion and vibrations growing without bound, once the wind velocity exceeds the critical one [12]. This phenomenon is related to the appearance of an axial flow behind the cable, which velocity $U_{\mathrm{a}}$ increases with wind uniform velocity $U$ and with the cable yawing angle. Instability appears when $U_{\mathrm{a}}>0.3 U$ for yawing angles greater than $25^{\circ}$ [13]. More recently Matsumoto et al. [14] related dry inclined galloping to Kármán vortex mitigation and distinguished between divergent-type galloping (DIG) and unsteady galloping. The latter is characterized by unsteady and not so large vibration amplitude, so it might not interfere directly with the safety of inclined cables.

Experiments [15] and field observation [14] indicate that dry inclined galloping can be ignored for normally spaced cables (at least $10 \mathrm{D}$ ) with damping ratio $\xi>0.3 \%$ (external damped cables) which approximately corresponds to

$$
S c_{0}=\frac{m \xi}{\rho D^{2}}>3
$$

\section{E. Rain Wind Induced Vibrations}

An exhaustive description of this phenomenon can be found in [1]. Designer wants to predict the occurrence of rain wind induced vibrations and set up counter-measures (for example, hydraulic dampers installed at cable ends). This can be achieved with the simplified model by Geurts and van Staalduinen [16]. They estimate the critical wind speed $U_{\text {cr }}$ for rain wind induced vibrations and the maximum amplitude of vibration $y_{0}$ given by

$$
U_{\mathrm{cr}}=\frac{4 m \xi \omega_{\mathrm{e}}}{-\rho D\left(\frac{\mathrm{d} C_{y}}{\mathrm{~d} \alpha}+C_{\mathrm{D}}\right)}
$$

and

$$
\left(\omega_{\mathrm{e}} \frac{y_{0}}{U}\right)^{2}=\frac{8}{\frac{\mathrm{d}^{3} C_{y}}{\mathrm{~d} \alpha^{\prime 3}}}\left(-\frac{\mathrm{d} C_{y}}{\mathrm{~d} \alpha^{\prime}}-\frac{2 \xi m \omega_{\mathrm{e}}}{\frac{1}{2} \rho U D}\right)
$$

where $\omega_{\mathrm{e}}$ is the natural circular frequency of cable in $\mathrm{rad} / \mathrm{s}$, and $C_{y}$ is the coefficient for loading in the vertical direction and $\alpha^{\prime}$ is the relative angle of attack. The authors adopt values of -0.8 and 54 for $\frac{\mathrm{d} C_{y}}{\mathrm{~d} \alpha^{\prime}}$ and $\frac{\mathrm{d}^{3} C_{y}}{\mathrm{~d} \alpha^{\prime 3}}$ respectively. These key values result from wind tunnel test of a smooth cable model with an artificial upper rivulet.

According to [15] rain wind induced vibrations can be suppressed when

$$
S c_{0}=\frac{m \xi}{\rho D^{2}}>10
$$

for stays with no surface treatments. The necessary damping ratio can be also obtained from (20), adopting appropriate limits for $y_{0}$, suitable to avoid alarming bridge users. It is reasonable to set $y_{0, \max }=D$; moreover, $y_{0, \max }=0.5 \mathrm{D}$ make vibrations virtually unnoticeable [15]. For user comfort and safety, in Eurocode EN1993-1-11 the limit $y_{0, \max }=L / 500$ is prosposed, instead, with a moderate wind velocity of $15 \mathrm{~m} / \mathrm{s}$, but for long stays this could result less restrictive.

Table $\mathrm{V}$ shows the damping requested for rain wind induced vibrations suppression in the stays of the considered bridge. In the table, case A $\left(\xi_{\text {req,A }}\right)$ refers to (21), that is independent both on wind uniform velocity and on cable stay natural frequency; case B $\left(\xi_{\text {req,B }}\right)$ refers to (20), assuming $y_{0, \max }=0.5 \mathrm{D}$ and $U=20 \mathrm{~m} / \mathrm{s}$; this latter value derives from field observations, demonstrating that rain wind induced vibrations occur when the wind speed varies in the range $(5 \div 20) \mathrm{m} / \mathrm{s}$. 
It can be highlighted, the design case $\mathrm{B}$ leads to less damping requirements for shorter stays (\#3 to \#10).

TABLE V. REQUESTED DAMPING FOR RAIN WIND INDUCED VIBRATIONS SUPPRESSION.

\begin{tabular}{rrrr|rrrrr}
\hline Stay & $\begin{array}{c}D \\
(\mathrm{~mm})\end{array}$ & $\begin{array}{c}m \\
(\mathrm{~kg} / \mathrm{m})\end{array}$ & $\begin{array}{c}\xi_{\mathrm{req}, \mathrm{A}} \\
(\%)\end{array}$ & $\begin{array}{c}W_{0, \max } \\
(\mathrm{m})\end{array}$ & $\begin{array}{c}U_{\mathrm{m}} \\
(\mathrm{m} / \mathrm{s})\end{array}$ & $\begin{array}{c}\omega_{1} \\
(\mathrm{rad} / \mathrm{s})\end{array}$ & $\begin{array}{c}\xi_{1, \text { req, }} \mathrm{B} \\
(\%)\end{array}$ & $\begin{array}{c}U_{c e} \\
(\mathrm{~m} / \mathrm{s})\end{array}$ \\
\hline 1 & 230 & 300 & 0.21 & 0.115 & 20 & 4.50 & 0.08 & 159 \\
2 & 55 & 17 & 0.22 & 0.028 & 20 & 7.09 & 0.22 & 160 \\
3 & 55 & 17 & 0.22 & 0.028 & 20 & 7.94 & 0.20 & 160 \\
4 & 230 & 300 & 0.21 & 0.115 & 20 & 9.17 & 0.04 & 156 \\
5 & 60 & 20 & 0.22 & 0.030 & 20 & 13.70 & 0.10 & 159 \\
6 & 65 & 24 & 0.22 & 0.033 & 20 & 12.93 & 0.10 & 159 \\
7 & 65 & 24 & 0.22 & 0.033 & 20 & 9.12 & 0.15 & 160 \\
8 & 65 & 24 & 0.22 & 0.033 & 20 & 8.11 & 0.16 & 160 \\
9 & 70 & 27 & 0.22 & 0.035 & 20 & 6.95 & 0.18 & 160 \\
10 & 70 & 27 & 0.22 & 0.035 & 20 & 6.25 & 0.20 & 160 \\
11 & 70 & 27 & 0.22 & 0.035 & 20 & 5.63 & 0.22 & 160 \\
12 & 75 & 31 & 0.22 & 0.038 & 20 & 5.08 & 0.23 & 160 \\
13 & 75 & 31 & 0.22 & 0.035 & 20 & 4.65 & 0.25 & 160 \\
14 & 75 & 31 & 0.22 & 0.038 & 20 & 4.29 & 0.27 & 160 \\
15 & 75 & 31 & 0.22 & 0.038 & 20 & 4.02 & 0.29 & 160 \\
16 & 75 & 31 & 0.22 & 0.038 & 20 & 3.71 & 0.31 & 160 \\
17 & 70 & 27 & 0.22 & 0.035 & 20 & 3.80 & 0.33 & 160 \\
\hline
\end{tabular}

\section{v. Concluding remarks}

The relevant issue of vibration phenomena directly induced by wind in cable-stayed bridges has been presented and investigated for a significant case study. In particular, buffeting, von Kármán vortex-shedding, dry inclined galloping and rain wind induced vibrations have been considered and the required necessary damping has been evaluated.

The results show that for the stays of the considered bridge buffeting is a self-limiting phenomenon and vortexshedding it is not relevant.

Instead a critical damping ratio of $0.3 \%$ on the first mode is obtained to control both dry inclined galloping and rain wind induced vibrations.

The obtained results are in good agreement with the actual requirements provided by EN1993-1-11 and by the Federal Highway Administration [15].

\section{References}

[1] E. de Sá Caetano, Cable Vibrations in Cable-Stayed Bridges. IABSEAIPC-IVBH, 2007.

[2] J. Wianecki, "Cables wind excited vibrations of cable-stayed bridges," in 5th International Conference on Wind Engineering, pp. 1381-1393, 1979

[3] Transportation Research Board and National Academies of Sciences, Engineering, and Medicine, "Inspection and Maintenance of Bridge Stay Cable Systems". Washington, D.C.: Transportation Research Board, 2005.

[4] J.P. Den Hartog; "Mechanical Vibrations", McGraw-Hill, New York, 1934.

[5] R. Castelluccio, "Il nuovo ponte strallato sull'Arno a Figline Valdarno," Università di https://etd.adm.unipi.it/theses/available/etd-09082016-181846/, 2016.

[6] A. Mehrabi and H. Tabatabai, "Unified finite difference formulation for free vibration of cables," Journal of Structural Engineering, vol. 124, no. 11, pp. 1313-1322, 1998.

[7] H. M. Irvine, "Free Vibrations of Inclined Cables," Journal of the Structural Division, vol. 104, no. 2, pp. 343-347, 1978.
[8] W. Shi, C. Wang, D. Coles, and A. Roshko, "Experiments on flow past circular cylinders at large Reynolds numbers," Journal of Wind Engineering and Industrial Aerodynamics, vol. 49, pp. 348-351, 1993.

[9] H. Yamaguchi and Y. Fujino, "Stayed cable dynamics and its vibration control," in Bridge Aerodynamics, A. Larsen and S. Esdahl, Eds. Balkema, pp. 235-253, 1998.

[10] Y. Fujino, D. M. Siringoringo, T. Nagayama, and D. Su, "Control, simulation and monitoring of bridge vibration - Japan's recent development and practice," in IABSE-JSCE Joint Conference on Advances in Bridge Engineering-II, pp. 61-74, 2010.

[11] T. Sarpkaya, "A critical review of the intrinsic nature of vortexinduced vibrations," Journal of Fluids and Structures, vol. 19, pp. 389-447, 2004.

[12] G. Matteoni, C. T. Georgakis, F. Ricciardelli, M. Arentoft, H. Koss, and E. Svensson, "Understanding and simulating vibrations of plain bridge cables under varying meteorological conditions: Wind tunnel experimental work and analytical modelling," DTU Tryk, 2014.

[13] M. Matsumoto, "Observed behaviour of prototype cable vibration and its generating mechanism," in Bridge Aerodynamics, A. Larsen and S. Esdahl, Eds. Balkema, pp. 189-211, 1998.

[14] M. Matsumoto, T. Yagi, H. Hatsuda, T. Shima, M. Tanaka, and H. Naito, "Dry galloping characteristics and its mechanism of inclined/yawed cables," Journal of Wind Engineering and Industrial Aerodynamics, vol. 98, no. 6-7, pp. 317-327, 2010.

[15] S. Kumarasena, N. P. Jones, P. Irwin, and P. Taylor, Wind-Induced Vibration of Stay Cables. Federal Highway Administration, 2007.

[16] C. P. W. Geurts and P. C. van Staalduinen, "Estimation of the effects $o$ rain-wind induced vibration in the design stage of inclined stay cables," presented at the Wind engineering into the 21 st century, vol. 2, pp. 885-892, 1999.

[17] EN1993-1-11: "Eurocode 3: Design of steel structures - Part 1-11: Design of structures with tension components." CEN, Brussels, 2010. 